\title{
Genetic Diversity Assessment of Luffa aegyptiaca Landraces Endemic in Egypt Based on Some Molecular Markers
}

\author{
Mohammad Abdel Sttar Al-Tahlawy, Mahmoud Abdel Aziz \\ Ibrahim1, Mohamed Ahmed Matter*, Mervat El -Sayed \\ Mohamed $^{2}$ and Mahmoud Mohamed Sakr
}

Plant Biotechnology Department, Genetic Engineering and Biotechnology Division, National Research Centre, 33 El Bohouth St. (former El-Tahrir St.), Dokki, Giza P.O. 12622, Egypt

Key words: Genetic diversity, Luffa aegyptiaca, Endemic landraces, Molecular markers

\begin{abstract}
Luffa aegyptiaca is a popular climbing herb endemic in Egypt. We studied the genetic diversity among ten Luffa landraces (Cairo, Beni Suef, Menoufiya, Damietta, Banha, Aswan, Kafr el-Sheikh, Bir el-Abd, MarsaMatruh and Asyut) collected from different districts in Egypt. The results obtained from DNA fingerprinting revealed that there were polymorphic loci with average percentage of 44.6 among collected landraces whereas polymorphic loci obtained from SDS-PAGE were $23 \%$. Discrimination between landraces was more efficient by using RAPD-PCR marker than total proteins SDS-PAGE which showed a limited level of intraspecific diversity.
\end{abstract}

\section{Introduction}

According to (USDA 2014), the species LuffaegyptiacaMill.(syn. L. cylindricaM. Roem.) is a member Cucurbitaceae. It is a popular climbing herb endemic in Egypt. They are abundant in suburban and rural areas, naturally around irrigation canals or cultivated for ornamental and other economical uses. Their fruits have a distinct morphological pattern differ from the other species. To our information, genetic characterization of Luffa aegyptiaca germplasm found

*Author for correspondence: <nhmatter@yahoo.com>. ${ }^{1}$ Molecular Biology Department, Genetic Engineering and Biotechnology Division, National Research Centre, 33 El Bohouth St. (former ElTahrir St.), Dokki, Giza P.O. 12622, Egypt. ${ }^{2}$ Chemistry Department, Faculty of Science, Cairo University, Giza, Egypt. 
throughout different districts of Egypt using molecular markers such as RAPD or SDS-PAGE. In the present study, the Luffa germplasm was collected from diverse agro-ecological regions of Egypt to determine the magnitude of genetic differences of Luffa germplasm based on total seed protein profile and RAPDPCR. Ten landraces of Luffa were collected from their growing habitats from different geographic regions in Egypt.

Genetic diversity represents the intrinsic differences between the members of the population (Tolentino et al. 1997). Any population with a large genetic pool has a greater chance of surviving and adapting with environmental challenges than a population with a limited genetic variability. This is because some of individuals may have inherited traits that cope better with stress factors. Reduced genetic diversity within a species can result in the loss of these useful and desirable traits. In plant breeding programs, these genetic variants can be used to improve existing traits and create new varieties. In addition, studying genetic diversity within a species is one of the key steps for developing a suitable conservation strategies and effective utilization of genetic resources (Paterson et al. 1991).

Molecular markers, such as RAPD, ISSR and SDS-PAGE, have a number of perceived advantages over the morphological characters assessment of genetic diversity. Most of the morphological characters are sensitive to environmental conditions and growth stages whereas molecular markers are insensitive to such factors and are abundantly present. Sodium dodecyl sulfate-polyacrylamide gel electrophoresis (SDS-PAGE) is mostly thought as a reliable means for the reason that total seed proteins are mainly free of environmental variations (Javaid et al. 2004, Iqbal et al. 2005). Random amplified polymorphic DNA (RAPD) is a sensitive and fast technique, requires the use of no radioactive probes, and is easily performed. RAPD markers are limited in their usefulness, however, in that they are dominant alleles, so it is necessary to prepare many closely linked markers to insure reliable comparisons among plant populations (Roberts, 2014).

\section{Materials and Methods}

Mature seeds of Luffa aegyptiaca were collected from their growing habitats in Egypt. Ten landraces samples from different districts (Table 1) were used to study the total seed protein variations among them. In addition, 7-days seedlings germinated on a sterile media inside plant tissue culture incubator were used for DNA isolation and to assess their genetic relationships using similarity index and dendrogram. 
Two hundred mg of decorticated seeds was grinded with addition a pinch of acid-washed sand. One $\mathrm{ml}$ of extraction buffer $(20 \mathrm{mM}$ Na-phosphate $\mathrm{pH} 7.2$ with $0.2 \mathrm{M} \mathrm{NaCl}$ ) was added and the homogenate was transferred to a clean 1.5 $\mathrm{ml}$ Eppendorf tube. The homogenate was mixed by vortex before incubation overnight at $4^{\circ} \mathrm{C}$, and then centrifuged at $14000 \mathrm{rpm}$ for $15 \mathrm{~min}$. The clear supernatant $(\sim 900 \mu \mathrm{l})$ was transferred to a new $1.5 \mathrm{ml}$ Eppendorf tube and filtered through $0.22 \mu \mathrm{m}$ Nalgene Syringe filter. The extracts were stored at $-20^{\circ} \mathrm{C}$.

Table 1. Egyptian districts from which Luffa landraces were collected.

\begin{tabular}{llll}
\hline District & Geographical location & District & Geographical location \\
\hline Cairo & $30^{\circ} 01^{\prime} \mathrm{N}, 31^{\circ} 14^{\prime} \mathrm{E}$ & BeniSuef & $29^{\circ} 05^{\prime} \mathrm{N}, 31^{\circ} 06^{\prime} \mathrm{E}$ \\
Menoufiya & $30^{\circ} 17^{\prime} \mathrm{N}, 30^{\circ} 58^{\prime} \mathrm{E}$ & Damietta & $31^{\circ} 24^{\prime} \mathrm{N}, 31^{\circ} 48^{\prime} \mathrm{E}$ \\
Banha & $30^{\circ} 27^{\prime} \mathrm{N}, 31^{\circ} 11^{\prime} \mathrm{E}$ & Aswan & $24^{\circ} 04^{\prime} \mathrm{N}, 32^{\circ} 57^{\prime} \mathrm{E}$ \\
Kafr el-Sheikh & $31^{\circ} 06^{\prime} \mathrm{N}, 30^{\circ} 56^{\prime} \mathrm{E}$ & Bir el-Abd & $31^{\circ} 02^{\prime} \mathrm{N}, 33^{\circ} 00^{\prime} \mathrm{E}$ \\
\hline MarsaMatruh & $31^{\circ} 19^{\prime} \mathrm{N}, 27^{\circ} 09^{\prime} \mathrm{E}$ & Asyut & $27^{\circ} 11^{\prime} \mathrm{N}, 31^{\circ} 04^{\prime} \mathrm{E}$ \\
\hline
\end{tabular}

Ten $\mu \mathrm{l}$ of the protein extracts were mixed with $10 \mu \mathrm{l}$ of sample buffer $(0.125$ $\mathrm{M}$ Tris-Cl, 4\% SDS, 20\% v/v glycerol, $0.2 \mathrm{M}$ DTT and 0.02\% bromophenol blue, $\mathrm{pH}$ 6.8), and then boiled in water bath for $3 \mathrm{~min}$ for protein denaturation. Ten $\mu \mathrm{l}$ of the prepared samples (contain about $50 \mu \mathrm{g}$ of protein) were resolved in $12 \%$ SDS-PAGE resolving gel. Electrophoresis run at constant current of $15 \mathrm{~mA}$, until the bromophenol blue tracking dye reached the bottom of the gel. The duration of the separation was about $2-3 \mathrm{hrs}$.

The separated polypeptide chains were fixed in the gel for one hour in fixing solution (10\% acetic acid, 10\% methanol and $40 \%$ ethanol). Molecular weights of the separated polypeptide chains were estimated using Page Ruler Broad range protein ladder (Thermo).

The fixed gel was stained by Blue Silver stain (Candiano et al. 2004) for at least $4 \mathrm{hrs}$. The gel was destained several times by distilled water until the background was clear. After destaining, the apparent polypeptide chains were analyzed and scored by the program Kapelan LabImage version 2.7.

The banding patterns obtained from SDS-PAGE were scored as present (1) or absent (0), each of which was treated as an independent character. Jaccard's similarity coefficient $(\mathrm{J})$ was used to calculate similarity between pairs of landraces. The similarity matrix was subjected to cluster analysis by unweighted pair group method with arithmetic means (UPGMA) and a dendrogram was generated using the program SPSS version 14.0. 
Seven-days germinated seedlings were used for DNA isolation that was performed using the CTAB method of Doyle and Doyle (1990) with some minor modifications.

RAPD was performed as described by Williams et al. (1990) with minor modifications. PCR amplification was performed in $25 \mu \mathrm{l}$ reaction mix (Table 2). Amplification was performed for 42 cycles (Table 3) using Biometra TPersonal thermal cycler. Concentrations of extracted genomic DNA were measured by NanoDrop 2000C (Thermo) and adjusted to $(20-30 \mathrm{ng} / \mu \mathrm{l})$ per reaction. Eight RAPD primers (10-mer oligonucleotides) were pre-selected based on their ability to generate reproducible and informative amplification patterns (Table 4).

Table 2. The components of RAPD-PCR mixture.

\begin{tabular}{ll}
\hline Reagent & Volume $(\mu \mathrm{l})$ \\
\hline Double distilled water & 9.875 \\
5X Green GoTaq Reaction Buffer & 5.0 \\
GoTaq DNA polymerase $(5 \mathrm{u} / \mu \mathrm{l})$ & 0.125 \\
$\mathrm{dNTPs}$ mix $(10 \mathrm{mM}$ each $)$ & 2.5 \\
$\mathrm{MgCl}_{2}(25 \mathrm{mM})$ & 1.5 \\
Primer $(10 \mathrm{pmol})$ & 3.0 \\
Genomic DNA $(20-30 \mathrm{ng} / \mu \mathrm{l})$ & 3.0 \\
Total volume & 25 \\
\hline
\end{tabular}

Table 3. RAPD-PCR cycle parameters.

\begin{tabular}{lccc}
\hline PCR step & Temp. $\left({ }^{\circ} \mathrm{C}\right)$ & Time $(\min )$ & No. of cycles \\
\hline Initial denaturation & 94 & 3 & 1 \\
Denaturation & 94 & 1 & 42 \\
Annealing & 36 & 1 & \\
Extension & 72 & 1 & 1 \\
Final extension & 72 & 7 & \\
Storage & 4 & & \\
\hline
\end{tabular}

Table 4.RAPD Primers.

\begin{tabular}{ll}
\hline Primer code & Primer sequence 5' $^{\prime}$ 3' $^{\prime}$ \\
\hline OPA-13 & CAGCACCCAC \\
A-02 & TGCCGAGCTG \\
A-03 & AGTCAGCCAC \\
A-04 & AATCGGGCTG \\
B-01 & GTTTCGCTCC \\
G-02 & GGCACTGAGG \\
G-03 & GAGCCCTCCA \\
Z-03 & CAGCACCGCA \\
\hline
\end{tabular}


The amplification products were electrophoresed in SCIE-PLAS horizontal mini-gel unit, model V-GEL on $2 \%$ agarose gel at constant voltage (100 V) in $1 \mathrm{X}$ SB buffer $(0.04 \% \mathrm{NaOH}, 0.225 \%$ boric acid) for approximately $1 \mathrm{hr}$, then the gels were stained by $0.2 \mu \mathrm{g} / \mathrm{ml}$ ethidium bromide. Samples were prepared by using $10 \mu \mathrm{l} \mathrm{PCR}$-product and 2 $\mu \mathrm{l}$ 6X DNA loading dye (Thermo). Molecular sizes of amplicons were estimated using a Gelpilot $100 \mathrm{bp}$ DNA ladder (Qiagen). After electrophoresis, the gels were documented under UV light on InGenius Gel Documentation System (Syngene). The apparent amplified bands were analyzed and scored by the program Kapelan LabImage version 2.7.

The banding patterns obtained from RAPD were scored as present (1) or absent (0), each of which was treated as an independent character. According to Prevost and Wilkinson (1999) the resolving power (Rp) of a primer is: $\mathrm{Rp}=\Sigma \mathrm{Ib}$ where $\mathrm{Ib}$ (band informativeness) takes the value of: $1-[2 \times(0.5-\mathrm{p})]$, $\mathrm{p}$ being the proportion of the analysed ten landraces containing the band. Jaccard's similarity coefficient (J) was used to calculate similarity between pairs of landraces. The similarity matrix was subjected to cluster analysis by unweighted pair group method with arithmetic means (UPGMA) and a dendrogram was generated using the program SPSS version 14.0.

\section{Results and Discussion}

The resulting protein profile of total seed protein extracts from ten landraces of Luffais presented in (Fig. 1). A total of 26 bands were scored among the ten landraces of which $6(23 \%)$ were polymorphic and 20 (77\%) were monomorphic. Size of the polypeptide bands ranged from 102.23 to $21.54 \mathrm{kDa}$. BeniSuef and Damietta landraces are characterized by a polypeptide band with MW 73.838 kDa. Similarly, Bir el-Abd and Asyut landraces are characterized by a polypeptide band with MW $37.238 \mathrm{kDa}$. A salient and unique polypeptide band with MW $55.052 \mathrm{kDa}$ is characteristic to MarsaMatruh landrace.

A dendrogram analysis based on UPGMA method grouped all the ten landraces into two major clusters (Fig. 2) with Jaccard's similarity coefficient ranging from 0.652 to 0.913 with average similarity indices $(78.7 \%)$. The cluster (1) included two landraces (Asyut and Kafr el-Sheikh) that was the most distant genetically from the remaining eight landraces belonging to the second cluster. The cluster (2) included three main subclusters (A, B and C). Three landraces (BeniSuef, Damietta and Banha) comprised subcluster (A) that exhibited close relationship among themselves with 91.3\% similarity. The subcluster (B) comprised of two landraces (Menoufiya and MarsaMatruh) that showed $87.5 \%$ similarity. The subcluster (C) comprised of two landraces (Cairo and Bir el-Abd) that showed $90.9 \%$ similarity. Aswan landrace stood in separate branch in this 
cluster but showed a closer relationship with subclusters (A and B) rather than with subcluster (C). The subclusters (A and B) as well as Aswan landrace evolved as one branch in the cluster (2) and the subcluster (C) evolved as another branch.

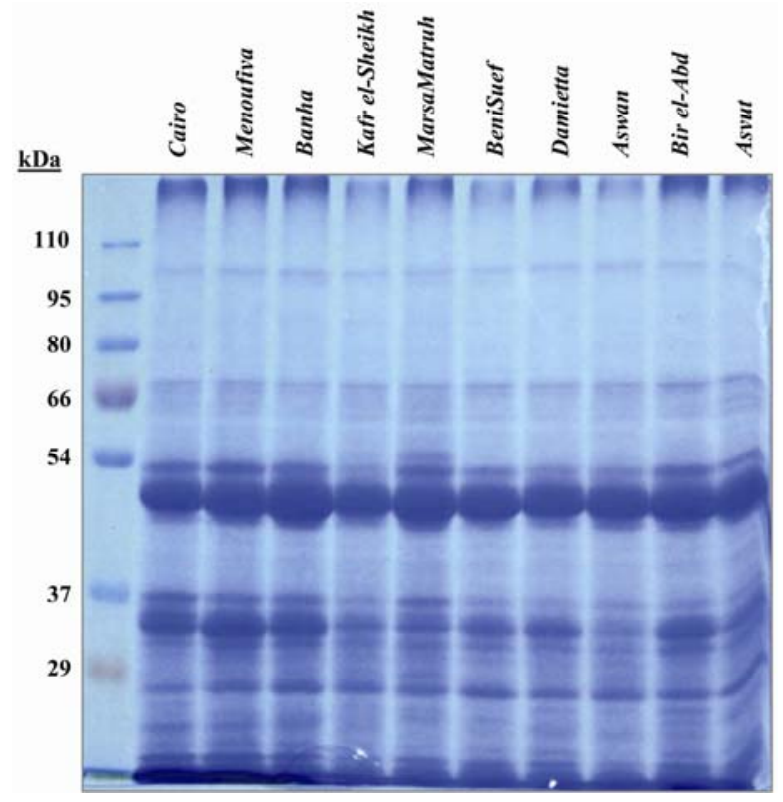

Fig. 1. 12\% SDS-PAGE of total seed protein extracted from ten landraces of Luffa.

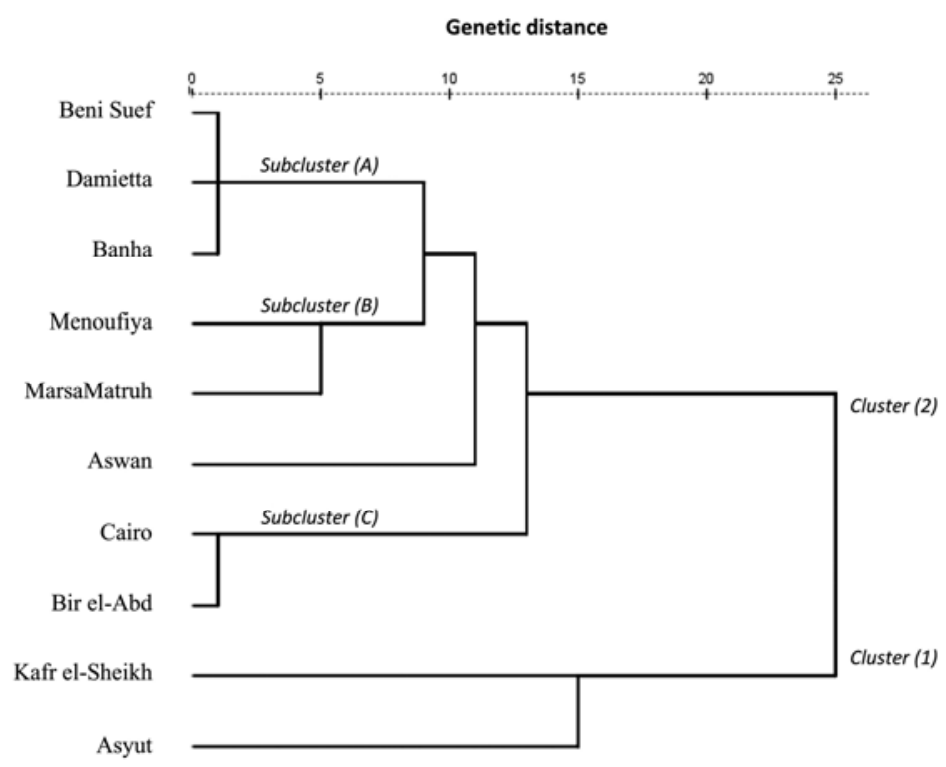

Fig. 2. UPGMA dendrogram representing genetic distances among ten landraces of Luffa based on seed protein profile variations. 
As shown in Table (4), the pre-selected eight random primers produced multiple band profiles that illustrated in Fig. (4) with a number of amplified DNA fragments varying from 3 to 13 and with an average of 6.25 loci per primer. All the amplified fragments varied in size from 151 to $1558 \mathrm{bp}$. Out of 50 amplified loci, 25 were found polymorphic with an average percentage of 44.6. The estimate of the primer resolving powers $(\mathrm{Rp})$ were found to be the highest for the primer B-01 (18.2) followed by primer OPA-13 (14.2) and was lowest for primer Z-03 (5.6).

A dendrogram analysis based on UPGMA method grouped all the ten landraces into two major clusters (1 and 2) (Fig. 3) with Jaccard's similarity coefficient ranging from 0.644 to 0.930 with average similarity indices $(78.7 \%)$. The cluster (1) included two landraces (Aswan and Asyut) that was the most distant genetically from the remaining eight landraces belonging to the second cluster. The cluster (2) included three main subclusters, (A and B) in one branch and $(C)$ in the second branch. Four landraces (Cairo, Bir el-Abd, Damietta and Banha) comprised of subcluster (A) in which the closest relationship was between the landraces (Cairo and Bir el-Abd) with 93\% similarity. The landrace (Damietta) showed more genetic relatedness with (Cairo \&Bir el-Abd) landraces than showed by (Banha) landrace. The subcluster (C) comprised two landraces (Menoufiya and Kafr el-Sheikh) that showed 89.7\% similarity. The subcluster (B) comprised two landraces (MarsaMatruh and BeniSuef) that showed 87.2\% similarity. The subclusters (A and B) showed a close relationship and evolved as one branch in the cluster (2) and the subcluster (C) evolved as another branch.

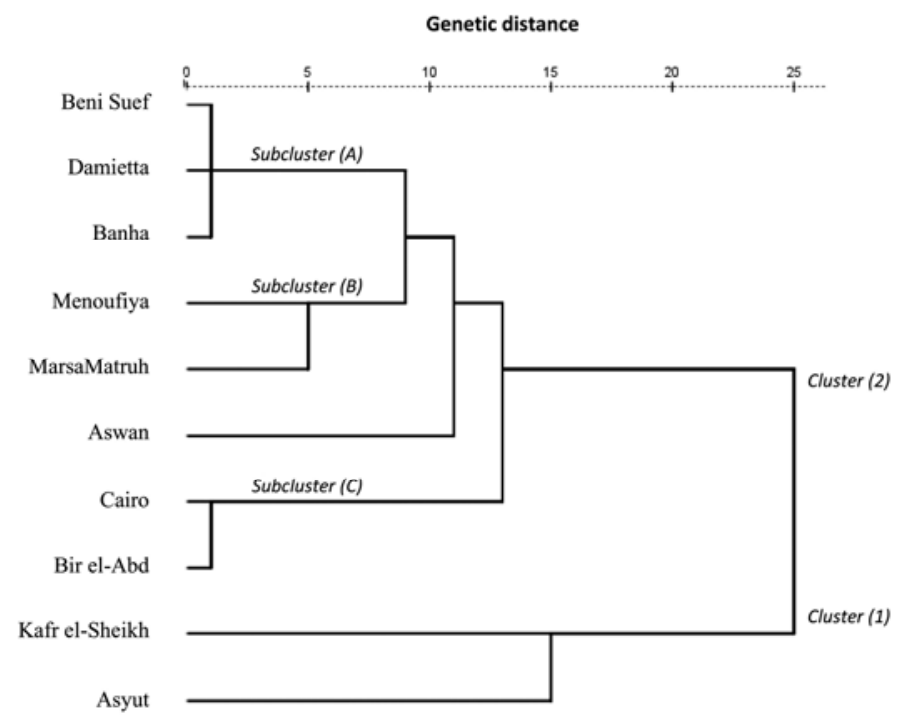

Fig. 3. UPGMA dendrogram representing genetic distances among ten landraces of Luffa based on RAPD-PCR analysis. 
The results of seed proteins electrophoresis exposed that a limited level of intraspecific diversity was present in the evaluated Luffa landraces. These results were supported by Tolentino et al. (1997) who reported a low intraspecific diversity for seed proteins among Luffa aegyptiaca accessions with almost the same value of similarity indices. RAPD marker was found to be more efficient in estimation of molecular diversity of the evaluated landraces of Luffa than electrophoretic variation of total seed protein profiles; as evident from large values of polymorphic loci. Similarity indices were found to be in agreement with those previously reported by (Prakash et al. 2014).

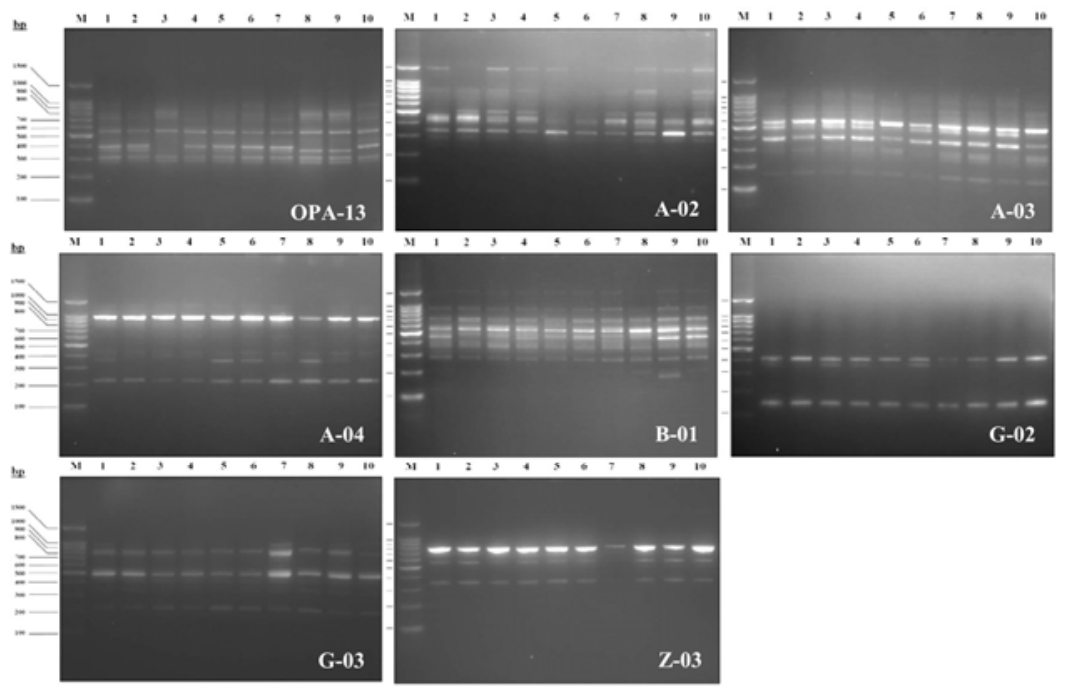

Fig. 4. DNA amplified fragments using the pre-selected eight random primers (OPA-13, A-02, A03, A-04, B-01, G-02, G-03, and Z-03). Lane (M): 100 bp DNA ladder with molecular weights given in bp. Lanes (l-10): RAPD-PCR products of ten landraces of Luffa.

The high level of similarity values suggest that germplasm collection represents a genetically related population, but the distribution of landraces among the groups did not follow any specific pattern in terms of the site of collection or geographic regions. The present study could be expanded by characterizing more different landraces to make a wide base gene pool with maximum diversity and/or characterizing the same landraces for other biological markers (isozymes, ISSR, RFLP, AFLP, etc.).

\section{Acknowledgements}

The authors sincerely thank the authorities of the National Research Centre (NRC), Egypt for financial support. 


\section{References}

Candiano G, Bruschi M, Musante L, Santucci L, Ghiggeri G, Carnemolla B, Orecchia P, Zardi L and Righetti P (2004) Blue silver: a very sensitive colloidal Coomassie G-250 staining for proteome analysis. Electrophoresis 9: 1327-1333.

Doyle J and Doyle J (1990) Isolation of plant DNA from fresh tissue. Focus 12: 13-15.

Iqbal S H, Ghafoor A and Ayub N (2005) Relationship between SDS-PAGE markers and Ascochyta blight in chickpea. Pakistan J. Bot. 37: 87-96.

Javaid A, Ghafoor A and Anwar R (2004) Seed storage protein electrophoresis in groundnut for evaluating genetic diversity. Pakistan J. Bot. 36: 25-29.

Paterson AH, Tanksley SD and Sorrells ME (1991) DNA markers in plant improvement. Advances in Agronomy 46: 39-90.

Prakash K, Pati K, Arya L, Pandey A and Verma M (2014) Population structure and diversity in cultivated and wild Luffa species. Biochemical Systematics and Ecology 56: $165-170$.

Prevost A and Wilkinson MJ (1999) A new system of comparing PCR primers applied to ISSR fingerprinting of potato cultivars. Theoretical and Applied Genetics 98(1): 107112.

Roberts K (2014) Using Random Amplified Polymorphic DNA (RAPD) Analysis to Examine Phylogenetic Distance among Different Plant Species. Available online at: http://www.bio-link.org/GMP/Rapdlab1.htm [Accessed: May - 2014]

Tolentino MIS, Laude RP and Viña ACD (1997) Genetic diversity analysis of Luffa species based on seed protein profile using SDS-PAGE. Philippin J. Crop Sci. 22(3): 141-146.

USDA, United States Department of Agriculture (2014) Natural Resources Conservation Service. Available online at http://plants.usda.gov/java/ClassificationServlet?source= display\&classid=LUFFA [Accessed: April - 2014].

Williams JGK,Kubelik AR, Livak KJ, RafalskiJA and Tingey SV (1990) DNA polymorphisms amplified by arbitrary primers are useful as genetic markers. Nucleic Acids Research 18(22): 6531-6535. 